\title{
Immunobiological Correlates of SIV Vaccine Vectors and Macaque Tropism
}

\author{
Joseph M. Antony
}

University of Toronto, King's College Circle, Toronto ON M5S1A8

\begin{abstract}
A R T ICLE INFO
A B S T R A C T

Review Article
VacRes, 2019
Vol. 6, No. 2, 23- 36
Received: January 15, 2020
Accepted:May 16, 2020
Pasteur Institute of Iran

*Corresponding Author: Joseph M. Antony. University of Toronto, King's College Circle, Toronto ON M5S1A8

Email: joseph.antony@utoronto.ca Tel/Fax: (+1) 8197448277

The field of HIV vaccines received a "boost" with around $30 \%$ protection obtained in the RV144 randomized, double-blind, efficacy trial in Thailand. Currently, 560 clinical trials in HIV vaccine development are registered as complete and results are expected from several of these studies. The modest success attained at this time may be attributed to early attempts at identifying an animal model to test vaccine efficacy. Macaque models of HIV-1 infection have revealed viral infection, transmission, pathogenesis, and prevention. Identification of simian immunodeficiency virus (SIV) and its related strains served as the macaque counterpart of HIV and through genetic engineering, enabled chimera development that explored how macaques respond to a human antigen as well. Along with understanding viral infection, it is worth exploring the genetic repertoire of macaques for determining how the major histocompatibility complex and anti-retroviral restriction factors offer barriers to viral replication.
\end{abstract}

KEYWORDS: Macaques, Tropism, Vaccine, Mucosa, SIV

\section{Citation:}

Antony J. Immunobiological Correlates of SIV Vaccine Vectors and Macaque Tropism. vacres. 2019; 6 (2) :23-36. DOI: 10.29252/vacres.6.2.23

\section{INTRODUCTION}

In spite of vast advances in medical science, there has been no better animal model of HIV than the macaque, which, owing to its immunology, reproductive physiology and anatomy that are highly comparable to humans, best reflects the progress and pathogenesis of HIV. Several aspects of HIV transmission and immunology are best studied in the macaque, even though humanized mouse models of HIV are now being developed [1]. These studies are essential for pre-clinical safety and efficacy testing of candidate vaccines and other therapeutics. While the macaque model of choice for several decades has been the Indian rhesus macaque, efforts to develop other macaque species as HIV models have resulted in the use of the cynomolgus macaque and the pigtail macaque for testing vaccine efficacy. Needless to say, the choice of a particular macaque model is significantly affected by the vaccine being tested both in terms of immunologic response and control of viremia. This review explores immunobiological responses in the macaque to SIV and its related vectors and highlights the impact of host immunogenetics on HIV vaccine development.

The need for developing new macaque models for HIV vaccine studies is compelled by the fact that not all macaques are equally permissive to various vaccine vectors. The two most common macaque species currently used in HIV research are the cynomolgus macaque (Macaca fascicularis) [2] and the rhesus macaque (Macaca mulatta) [3]. Even though they diverge by $\sim 2$ million years, cynomolgus and rhesus macaques are $99.6 \%$ genetically similar [4], [5]. However, these macaque species have unique region-specific characteristics that have been unravelled by genetic sequencing. This is evident in the case of rhesus macaques, which are of Indian, Chinese and Indian/Chinese hybrid species [6], or cynomolgus macaques, which may be of Mauritian, Filipino or Vietnamese origin or a mix of these depending on the geographic source of the animals. Macaque hybridization between vastly different macaque species and subsequent genomic exchanges is exemplified by the estimation that $\sim 30 \%$ of the genome of Vietnamese cynomolgus macaque is of Chinese rhesus macaque origin [7] while their genetic divergence is estimated to be approximately $0.4 \%$ [8], [4]. While it is important to acknowledge that animals are inefficient efficacy and safety models, currently available options are our best bet in our search for vaccines, which require better understanding of immunological variability. A recent study [9] profiling immune signalling between and within species of macaques, mice, and healthy humans showed significant differences in the frequencies of many populations of blood cells (Fig. 1). Humans, mice and African green monkeys (AGM) have fewer CD4+- CD8+ T cells compared to macaques; mice have 10-fold lower numbers of neutrophils than all primates; all non-human primates have approximately three-fold more B lymphocytes than humans, and mice have approximately 10 -fold more B lymphocytes than humans; humans have a higher ratio of classical to non-classical monocytes than any other species 
examined [9]. These findings indicate that model species should be evaluated based on their relevance to the experiment at hand.

Regardless of gene similarities, cynomolgus macaques are very different from rhesus macaques and this is exemplified by the inability of rhesus macaques to be infected by the human varicella zoster virus (VZV) [10] unlike the cynomolgus macaque [11], which makes the latter an ideal candidate animal model to examine the development of varicella-based vectors against SIV/HIV [11]. Further, a rhesus macaque-derived cytomegalovirus (CMV)-based BAC vector (RhCMV-eGFP) was not able to infect cynomolgus macaque [12], while rhesus macaques were previously shown to be permissive to the same vector [13]. Yet another example is that of a mutant SIVmac239 virus that established infection in both rhesus and pigtail macaques. Viremia was rapidly suppressed in pigtail macaques to levels of $<15-50$ copies/ml in contrast to rhesus macaques and reflect species-specific differences, with virus control being superior in pigtailed macaques that typically exhibits more rapid disease progression following wild-type SIV infection [14]. Therefore, host species-specificity and tropism have to be considered in earnest while designing vectors, in addition to other factors that influence the outcome of a vaccine trial in macaques.

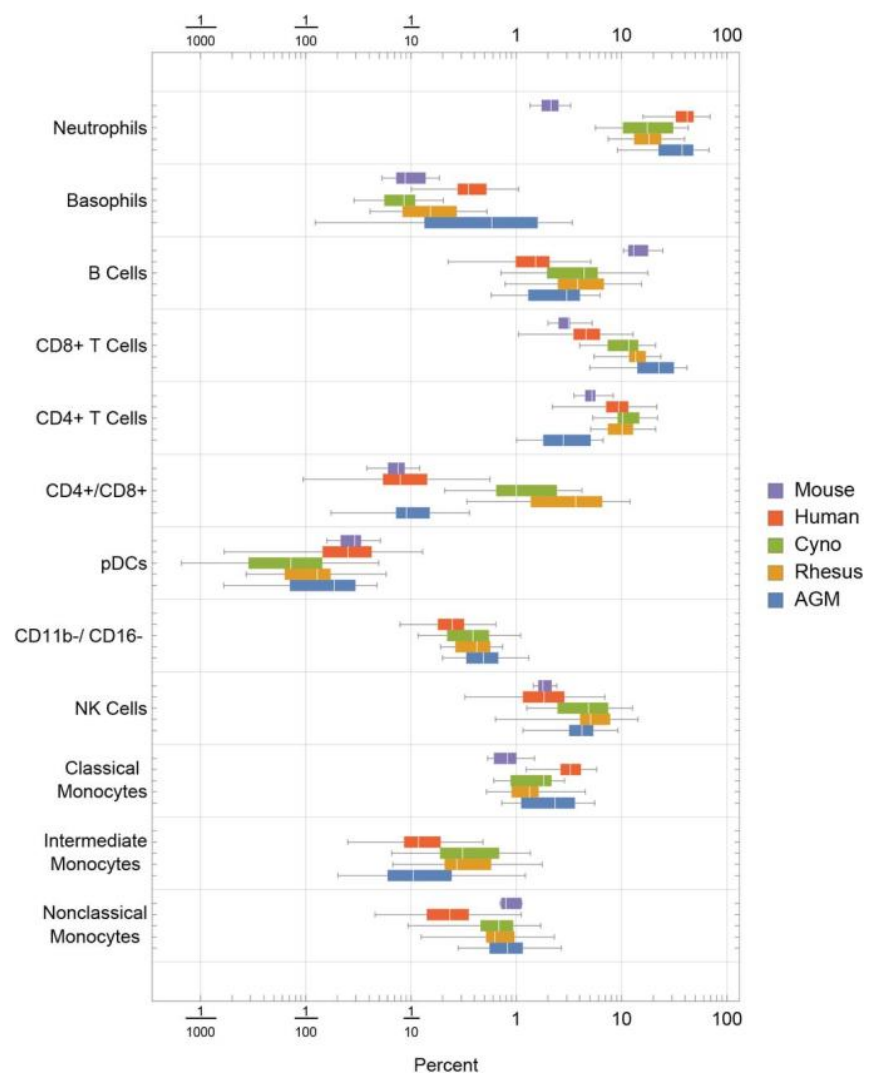

Fig. 1: Percentage of the total number of gated cell types by species [9]

\section{Macaques as HIV Models of Disease Pathogenesis}

Macaques belonging to the Cercopithecoidea superfamily are currently being used in AIDS vaccine research and mainly comprise rhesus [3], cynomolgus [2] and to a lesser extent, pigtail macaques (Macaca nemestrina) [3]. Rhesus macaques are mainly of Indian or Chinese origin, though smaller populations of Burmese origin are also used in SIV research [15]. Geographic concordance and phylogenetic analyses corroborate the notion that multiple cross-species transmission events of an SIV strain named SIVcpz from primates to humans gave rise to all known HIV-1 and HIV-2 groups and subtypes [16]. African non-human primates such as the sooty mangabeys, AGMs and mandrills support high burdens of SIV without overt clinical disease manifestations but show lower levels of immune activation than HIV-infected humans or SIVinfected Asian macaques. Rhesus, cynomolgus and pigtail macaques do not harbour SIV in the wild but when inoculated with SIV or SHIV, they exhibit clinical and immunological features of HIV infection in that there is a decline in CD4+ T cells and animals progress to AIDS or SIV-AIDS. The remarkable similarities are reinforced by the utilization by SIV of the same receptor for attachment and entry into cells as HIV.

Morphological Variations Among Macaques that Facilitate Pre-Clinical Testing

Chinese-origin rhesus macaques differ from those of Indian origin in genetics, morphology, behaviour and physiology, which has been reflected in the fact that Chinese rhesus macaques have significantly longer survival times and are less susceptible to infection by pathogenic SIVs/SHIVs than their Indian counterparts. Further, steady state plasma viral load (set point viremia) is significantly lower in Chinese macaques and they strongly respond to viral antigens, with differing patterns of cytokine secretion and expression of CCR5 in CD4+ T cells [17-23].

In terms of viral loads and disease progression, cynomolgus macaques better reflect human HIV infection than rhesus macaques. This obviously has its benefits and disadvantages as well. Due to their smaller size than their rhesus counterparts, cynomolgus macaques might be advantageous from a therapeutic standpoint as lower doses will be required on a body weight basis Further, the basic anatomy, vaginal $\mathrm{pH}$ and microbial flora in the vagina and rectum are similar to that of humans [24], thereby facilitating the extrapolation of pre-clinical data, though anatomical features such as a small vaginal vault make colposcopy and vaginal biopsies difficult. Rhesus macaques also share similar aspects of vaginal anatomy, particularly during certain phases of the menstrual cycle, which have made these macaques a popular choice for therapeutic approaches such as microbicides. Pigtail macaques on the other hand, have higher viral loads and more rapid progression to disease than HIV-infected humans. Pigtail macaques also share similar aspects of vaginal and rectal flora with that of humans. A significant advantage with using pigtail macaques is their susceptibility to vaginal exposures of low doses of SIV/SHIV, which resemble that of HIV-infected patient semen viral load, obviating the need for high doses of the virus or application of progestin-based hormones to thin vaginal epithelium to facilitate viral entry [25].

The Mucosa is the Most Important Entry Point for Establishment of Infection

To prevent HIV from gaining a foothold and to determine the kinetics of drug delivery in target areas, it is imperative to establish the paths of viral entry in the mucosa. The mucosal barrier is a dynamic entity that is subject to assaults on a constant basis and a healthy mucosal immune environment inhibits pathogen entry. The vaginal and rectal mucosa are affected by sex hormones and this is important for establishing infections due to the direct effect of sex hormones on the mucosal barrier function. As an example, Indian rhesus macaques treated with a sex hormone (Depot Medroxy Progesterone Acetate, DMPA) had higher levels of the gut homing receptor, $\alpha 4 \beta 7$ on $\mathrm{CD} 4+\mathrm{T}$ cells that are highly 
susceptible to SIV, particularly in the endocervix than in macaques treated with estradiol (E2). However, MAdCAM-1, the $\alpha 4 \beta 7$ ligand, was present in higher levels in the vaginal fluids of control and estradiol-treated animals but absent in those from DMPA-treated animals [26].

The female genital tract is thus unique because of its ability to respond to hormones, immune factors, commensal microbes and biochemical processes, all of which contribute to increased rates of heterosexual male-to-female HIV transmission when compared with female-to-male transmission. Therefore, efficacy will be improved if vaccines are able to target the female genital tract and induce local immunity. Human papilloma virus (HPV) naturally infects cervicovaginal keratinocytes and therefore might serve as efficient vectors for HIV vaccines. Plasmid-forming pseudovirions that encapsidate HPV capsid proteins are known to effectively deliver reporter genes to the female genital tract and in addition to transgene expression, also serve as adjuvants, engaging Toll-like receptors and facilitating the activation and maturation of antigen presenting cells. A common feature of vaccines that facilitate expansion and recruitment of $\mathrm{T}$ cells is the unwanted effect of recruiting susceptible $\mathrm{CD} 4+\mathrm{T}$ cells and thereby exacerbating viral replication. However, this was shown to be not true when HPV pseudovirions were used for vaccination against SIVmac251 challenge [27], with virus levels in mucosal tissues inversely correlated with anti-envelope CD4 T cell responses and CD8 T cells playing a role in virus control [28].

Macaque models allow stringent control of virus dose, strain and tropism, timing, mucosal route and status of mucosal tissues [29]. However, the complexity of human sexual practices make it difficult to study sufficiently large numbers of individuals [29], intrarectal or intravaginal routes of challenge reflect human sexual practices only to a certain extent, even though similar to human HIV infection, rhesus macaques carried the lowest risk of SHIV infection, when challenged orally, while the highest permeability was rectal followed by vaginal routes [29]. Nevertheless, primate laboratories working with the SIV model of macaques have not developed a standardized protocol for mucosal inoculation. Standardization of mucosal inoculation is important since it has been demonstrated by genetic analyses that over $78 \%$ of typical sexual transmissions originate from a single viral variant from among the diverse quasi-species in the infected donor [30]. Several features such as virus dose, number and frequency of inoculations, volume of inoculum, position of the animal during exposure and duration of the exposure, amount of mucosa exposed to the inoculum and virus dissemination sites as well as draining lymphatic tissues involved in infection are all important aspects to study viral transmission, pathology, prevention and treatment [30]. Intravaginal SIV infection is typically examined in rhesus macaque or pigtail macaque. The vagina is a multi-layered stratified squamous epithelium whose thickness is affected by the menstrual cycle, while the rectum is composed of a single layer of columnar epithelium [31]. The vagina therefore provides a more substantial physical barrier to infection. Due to this, compared to the intravenous route, 10,000 fold more SIV particles are needed to infect $100 \%$ of rhesus macaques intravaginally [32]. Compared to rhesus macaques that are seasonal breeders, pigtail macaques breed throughout the year and hence the latter might be preferred for vaginal studies [24]. Pigtail macaques have regular menstrual cycles and in addition to being more susceptible to vaginal chlamydia and trichomonal infection than rhesus macaques, they have higher states of immune activation and different frequencies of memory cells than rhesus macaques, which may lead to an accelerated progression to SIV-AIDS [33].

Vaccine-induced delayed SIVmac251 acquisition in females, but not male rhesus macaques, was attributed to better quality mucosal antibodies that afford better protection compared to males [34]. In a bid to refine current inoculation protocols and to determine where virus entry occurs and how infection disseminates from the mucosal entry sites, dual reporter SIV vector [35] and mucosal inoculations of dyes followed by magnetic resonance imaging were carried out recently [36]. Atraumatic application of one $\mathrm{ml}$ of viral inoculum for intrarectal challenges and two $\mathrm{ml}$ volume for intravaginal challenges was insufficient for reaching the distal descending colon, and could model rectal exposure in only $50 \%$ of the animals. A three $\mathrm{ml}$ intrarectal challenge, the volume of a typical macaque ejaculate, would more likely increase the consistency of contact between the mucosa and the inoculum. Nevertheless, other factors such as amount and consistency of feces are variables that can affect this estimation. For vaginal exposure, a two $\mathrm{ml}$ volume in sexually mature, nulliparous Indian rhesus macaques resulted in the inoculum contacting the entire vaginal vault but there was no penetration into the cervix. Using a different approach, a dual reporter system containing a non-replicating SIV-based vector preferentially infected the squamous mucosal epithelium and ectocervical barriers of the vaginal vault, along with ovaries and local draining lymph nodes only 48 hours after inoculation with a high dose of virus [35].

Another less frequently described aspect of SIV pathogenesis is the use of SIV/SHIV cell-free viral particles to evaluate preventive approaches. It must be taken into account that infectious HIV is primarily associated with semen, which comprises seminal plasma, spermatozoan cells, germ cells, leukocytes, epithelial cells and commensal microflora; plasma contains inflammatory factors, cytokines, peptides and antibodies. Macaque semen similarly contains leukocytes and SIV host cells. Studies have shown efficient transmission with cell-associated SIV in vaginally exposed progesterone-treated cynomolgus macaques [37] as well as intestinal mucosa to repeated intrarectal exposure to low amounts of SIV-infected peripheral blood mononuclear cells (PBMCs) [38]. This initiated an immune response in the receiver that may confer a protection against infection by the cell-associated virus, thereby resulting in allo-immunization against the major histocompatibility complex (MHC) of the donor, and anti-MHC antibodies generated by vaccines have significant impact on the outcome of SIV/HIV vaccine challenge in macaques [39]. In addition, viral infectivity in the semen is affected by its $\mathrm{pH}$, which in the macaque is slightly basic, ranging from 7 to 9 , similar to that of the average human semen ( $\mathrm{pH}$ 7.7). Compared to semen, the vaginal environment in humans is acidic with a $\mathrm{pH}$ ranging from 4 to 6 , which can therefore inactivate cell-free HIV. However, $\mathrm{pH}$ of the vaginal environment in macaques (rhesus, cynomolgus macaque and pigtails) ranges from 6 to 8 , which increases infectivity of cell-free SIV/SHIV in the macaque model [39]. Therefore, factors that regulate the complex microenvironment at portals of HIV entry need to be better understood for testing vaccine efficacy.

\section{Host Immunogenetics}

Anti-Retroviral Restriction Factors and Protection in Macaques

The genetic background of the host species, or even subspecies, is important for the purposes of grouping macaques 
for vaccination trials where host immunogenetics profoundly influence immunological responses and virological outcomes [3]. Foremost among these genetic players are the host antiretroviral restriction factors such as APOBEC3, TRIM5 $\alpha$, SAMHD1 and MHC alleles that influence the progress of disease in macaques infected with SIV. HIV can efficiently enter the cells of old world monkeys but encounters a block before reverse transcription, mediated by TRIM5 $\alpha$, a component of cytoplasmic bodies [40]. TRIM5 $\alpha$ targets the capsid protein of incoming lentiviral particles and inhibits subsequent steps of the replication cycle, including inhibition of reverse transcription immediately after viral entry into the cell and therefore is an important mediator of anti-retroviral innate immunity in mammals and confers resistance to HIV-1 infection in old world monkeys [41]. The susceptibility of pigtail macaques to HIV could partly be due to a dysfunctional TRIM5 $\alpha$ [42]. The macaque TRIM5 $\alpha$ gene displays considerable polymorphism in one of the domains leading to its classification into three classes giving rise to six different genotypes, which have been to shown to display divergent antiretroviral restriction characteristics. The cynomolgus macaques are positive for TRIM5Q, TRIM5CypA and TRIM5TFP genotypes, while the pigtail macaques are homozygous for TRIM5CypA. Rhesus macaques of Burmese, Chinese and Indian origin possess TRIM5 alleles, but the TRIM5CypA variant is absent in Chinese rhesus macaques, thereby making them less susceptible to SIV infection than the Indian rhesus macaques. Most rhesus macaques are homozygous or heterozygous for the least permissive TRIM5TFP allele. Interestingly, there is no significant effect of TRIM5 polymorphism on the replication of SIVmac251 in Chinese rhesus macaques or SIVmac32H/ixc in Indian rhesus macaques, suggesting that the effects of TRIM5 polymorphism on the evolution of SIV in macaques may be cohort and/or SIV strain specific [43]. Since many host genes dictate immunological responses to vaccines, the role played by the above mentioned restriction factors such as SAMHD1, TRIM5 $\alpha$ and MHC alleles that confer protection have to be factored in while designing studies.

\section{MHC Alleles and Protection in Macaques}

As CD8+ T cells are an integral component of the immune response against SIV, it is necessary to examine MHC expression in macaques so that $\mathrm{CD} 8+\mathrm{T}$ cell responses can be monitored during disease progression. The repertoire of MHC alleles and the level of expression of each of these alleles is a critical aspect of an immune response to SIV and the fact that MHC expression varies among distinct leukocyte subsets suggests that SIV tropism can have an impact on the immune response [44]. Characterization of MHC class I alleles allows us to identify the association of cytotoxic T lymphocytes (CTL) response to an immunodominant epitope derived from the SIV Gag region, which may ultimately influence the time of onset of disease in SIV-infected macaques. MHC alleles such as ManeA1*084:01 (previously named Mane-A*10) control SIV infection by CD8+ T cells [45] and immune escape mutations identified within CTL epitopes restricted by Mane-A $1 * 084$ are useful for designing vaccines for use in in pigtail macaques [46]. Indian rhesus macaques are known to have several MHC alleles that confer protection. Expression of Mamu-A $1 * 001$ is associated with significantly delayed disease progression in SIV/SHIV infections while Mamu-B*017, Mamu-A*1303 and Mamu-B*008 alleles are associated with favourable disease and control of SIV replication [47]. In the case of cynomolgus macaques, MHC alleles can affect the outcome of vaccine studies similar to that observed in rhesus macaques. Comparison of the MHC region between primates and nonhuman primates shows that the cynomolgus sequence varied compared to rhesus macaque, human and chimpanzee sequences by $0.48,4.15$ and $4.10 \%$ respectively [48], which implies considerable species-specific differences that vaccine design must deal with. MHC alleles in cynomolgus macaques

have been described in sufficient detail elsewhere [13].

\section{MHC Alleles and Protection in Humans}

MHC class I alleles such as human HLA-B*027 and HLA$B * 057$ are associated with slow progression of HIV-1 disease [49] while HLA-B*22, HLA-B*35, and HLA-B*44 in humans are associated with shorter survival time [50]. With respect to MHC class II molecules, there is evidence in the RV144 trial for envelope [51]-specific IgA antibodies to be associated with increased risk of HIV acquisition specifically in individuals with DQB1*06. Higher IgG antibody responses to HIV envelope amino acid positions 120 - 204 were associated with decreased risk of acquisition and increased vaccine efficacy only in the presence of DPB $1 * 13$. Overall, the underlying genetic findings indicate that HLA class II modulated the quantity, quality, and efficacy of antibody responses in the RV144 trial [52]. Unlike SIV vaccine studies in cynomolgus macaques where MHC/TRIM typing was either not carried out or not reported [2], most studies in rhesus macaques reported these data. It is essential for macaque studies to conduct MHC typing of the animals such that influence of protective alleles in the vaccinated or treated groups could be ruled out as a possible mechanism for the outcome of the study.

\section{Psychosocial Features of Animal Husbandry}

An often-neglected aspect of animal housing facilities is the suppression of vaccine efficacy due to neuropsychoimmune effects faced by macaques in a social environment. During competitive encounters, dominance rank is established among macaques, leading to some individuals yielding to others in the group. Low dominance rank in macaque colonies can lead to chronic stress, immune compromise and reproductive dysregulation. Particularly in female rhesus macaques, this can cause alterations in glucocorticoid and sex steroid hormone levels [53], in addition to disruption in serotonergic and dopaminergic signalling [54], and very importantly, in the context of SIV infection and immune response, changes in lymphocyte count and proliferation [55].

\section{Evaluation of Vaccine Efficacy}

SIV vaccine efficacy depends on induction of robust and long-lasting antibodies against envelope glycoprotein with potent neutralizing and effector functions to prevent acquisition of infection and induction of cytolytic $\mathrm{T}$ cell responses against Gag for controlling viral replication [34]. Frequently, due to lack of systematic vaccination protocols and uniformity in the type of challenge strains, viral doses and macaque species used, there are difficulties in evaluation of vaccine efficacy and identification of correlates of protection associated with vaccination against SIV. On examination of the efficacy of various vaccine vectors in animal trials, most rhesus macaques showed at least 1-2 log lower viremia, even though animals protected were not high (Table 1). A vaccine regimen comparing cellular responses to ALVAC/Env, RepAd/Env, DNA \& Env, DNA and Peptide/MVA/ in rhesus macaques 
showed that all vaccine regimes, particularly DNA vaccines (highest frequency of $7.5 \%$ ), induced antigen-specific CD8+ T cells in the vagina. While only one of three animals was positive with ALVAC, cellular responses were not induced with peptides. IgA and IgG were detected in the mucosa of all vaccines, though $\operatorname{IgG}$ was higher than $\operatorname{IgA}$ in animals with antigen-specific CD8+ $\mathrm{T}$ cell response [56].

With very few exceptions [57], there are no studies where protection has exceeded $50 \%$ in SIV-infected rhesus macaques. High seropositivity to adenoviral vectors in the general population might be the greatest challenge in vaccine development as noted with the setbacks associated with replication defective Ad5 vectors in HIV vaccine clinical trials (HVTN505 and STEP). Of many adenoviruses that have been tested, $50 \%$ protection was obtained against pathogenic challenge [58], but it seems that $\operatorname{Ad} 26$ strain offered the best protection when combined with a robust prime boost strategy [56]. Ad5, Ad6 and Ad7 did not offer significant protection (Table 1). More recently, replicating Ad5hr-recombinants encoding SIV-Gag and/or SIV-nef in addition to SIVenv/rev, boosted with SIVgp120 or polypeptide of CD4 binding site of SIV env, showed $39 \%$ of animals protected against intrarectal challenge of SIVmac251 [59]. A similar level of protection against SIVmac251 was afforded by virus-like particles (VLPs) in rhesus macaques [60]. This suggests that a strong immune response is being generated, but with adenoviruses, it seems that the prime boost combination might be working in its favour compared to other vectors that were employed. This was clearly not needed when RhCMV was used, owing to the unique nature of the cytomegaloviruses that exhibit persistent and latent infection, mediating their effects through $\mathrm{T}$ effector memory responses [61]. Most studies have used the Indian rhesus macaque though at least one study using Chinese origin rhesus macaques showed lower viremia in immunized animals in the context of adenoviral vectors [62].

\section{SIV Strains Used in Macaque Challenge Experiments}

Once the vaccine vector has been validated through in vitro studies and macaque model has been identified, the choice of challenge virus gains paramount importance. Pre-clinical macaque vaccine trials use either heterologous or homologous virus challenge, SIVmac251 and SIVmac239 being the principal strains used. SIVmac251 is a swarm whereas SIVmac239 is a clone and this needs to be considered for standardization of vaccine trials. SHIV SF162 and related strains are used in SHIV chimera-based vaccines (Table 1).

\section{SIVmac Strains}

SIVmac viruses have only $\sim 55 \%$ sequence homology with that of HIV-1 whereas they have $\sim 75 \%$ sequence homology with that of HIV-2 and a 54-80\% sequence homology with SHIVs. The SIVmac251 virus and SIVsmE660 were isolated from rhesus macaques naturally infected by SIVsm, and SIVmac239 is a derivative of SIVmac251 [63]. Whereas some such as SIVmac239 is highly pathogenic, others have been attenuated due to genetic deletions. SIVmac251-32H-C8 lacks $12 \mathrm{bp}$ in the nef gene, while SIVmac251-J5 displays limited pathogenicity [63]. Most challenge experiments in macaques have been performed using SIVmac251, which is a swarm virus or the pathogenic clone SIVmac239, as well as SIVsmE660, the latter showing low viral loads in the chronic phase, but nevertheless is a swam virus showing considerable variability between animals [63].

\section{SIV-SHIV Chimeras}

Among chimeric viruses, SHIV89.6 with HIV-1 env from patient isolate 89.6 and SIVmac239 has been used extensively for vaccine studies in rhesus and cynomolgus macaques [64, 65]. Highly pathogenic SHIVs such as SHIV-89.6P chimeric virus cause a profound depletion of circulating CD4+ T cells within 2-3 weeks of infection and development of AIDS-like disease within a year [66]. SHIV89.6P are either X4-or dual tropic and irreversibly destroy naïve and memory CD4+ T cells rapidly. Even though the HIV-1 env included in SHIV-89.6P was derived from a clone that used both CCR5 and CXCR4 coreceptors for entry into macaque $\mathrm{CD} 4+\mathrm{T}$ cells, sequential passage in macaques has selected for a SHIV-89.6P clone that is now deemed a pure $\mathrm{X} 4$ virus [67]. A relative drawback of SHIVs is the fact that their disease course is not typical of human AIDS in that infected animals become rapidly immunosuppressed immediately with dramatic loss of CD4+ cells and essentially "crash and burn" with almost always gutrelated pathology and wasting within the first few weeks. SHIV89.6KB9, a strain derived from Indian rhesus macaque, showed improved pathogenicity when passaged in cynomolgus macaques (resulting in SHIV89.6cy243) due to an 8-amino acid change at the junction between the HIV-1 and SIVmacgp41 cytoplasmic tail gene sequence [66].

As there is an emerging shift in immune correlates of protection from cell-mediated immune response to that of nonneutralizing antibodies to control HIV infection based on the results of the RV144 trial [68], there is a need to develop SHIVs that recapitulate the mechanisms of natural infection and antibody action in macaques. Tier 1 HIV strains are highly neutralization sensitive and SHIVSF162P4 is an example of a chimeric strain, whereas Tier 2 strains, such as R5-tropic SHIVSF162P3, are less sensitive to neutralization, and in nonhuman primate models both are essential for vaccine discovery. Unless provided at high doses, both these strains are rapidly cleared, but not newer strains such as SHIV-1157 [69].

\section{Challenge Routes}

Pigtail macaques inoculated intrarectally with SIVmneE11S clone, showed dramatic increases in total and SIV-specific IgA levels in rectal secretions compared to plasma and non-rectal mucosal samples [70]. A comprehensive study examining different routes of exposure in rhesus and cynomolgus macaques showed that the early plasma viral loads did not differ when administered SIVmac251/32H(1XC), SIVmac251, SIVsmm-3, SHIV89.6P (passaged in rhesus and cynomolgus macaques) orally, intrarectally, intravaginally or intravenous routes, though steady state SIV plasma viral RNA was lower in cynomolgus macaques compared with rhesus macaques [71]. Most studies comparing different routes of vaccine delivery were performed in rhesus macaques, particularly evaluating the bio-distribution and persistence of replication-competent adenovirus vectors expressing SIV transgenes. It is interesting to note that unlike replicationdefective vectors that maintain localized anatomic distribution, replication-competent adenovirus vectors are distributed throughout the macaque regardless of immunization route [72]. However, the same group showed that replication-competent Ad5-SIV induced mucosal IgA responses in mucosal (sublingual, rectal, vaginal, or nasal) tissues but the vaginal immunization route was found to generate the highest SIVspecific vaginal T-cell responses [73]. Similarly, live attenuated poxvirus vaccine (NYVAC-SIV) administered intranasally, intramuscularly, or intrarectally induced CD8+ T cells specific 
to the antigen (SIVgpe) in the mucosal tissues of immunized macaques [74]. On the other hand, it has also been noted that cutaneous or intramuscular immunization generates antigenspecific cells that may not migrate to mucosal sites as shown in macaques where mucosal immunization offered better protection than the subcutaneous route following intrarectal challenge with a SHIV strain [75]. Penile immersion in 109 SIVmac251 resulted in higher SIV RNA levels in the genital lymph nodes where virus is initially amplified [76].

\section{Challenge Doses Used in Macaques}

HIV is a weak virus with productive infection being a rare event since a minimum of 500 heterosexual contacts are needed to cause one productive infection [77]. HIV/SIV infection is established when a single virus spreads systemically after replication in mucosal tissues. Successful transmission of HIV via a mucosal route is dependent on multiple factors, including the viral dose present in the inoculating fluid (semen, vaginal fluid, breast milk), the integrity of the mucosa, and the number of target cells at the mucosa site. The dose of virus needed to establish infection is crucial to elicit an immune response. Since a majority of infections is initiated by a small number of transmitted viral variants, how the disease course is affected by virus dose and the number of variants in that dose becomes important. Experimental protocols in macaques generally follow one high dose of a SIV clone or a swarm to achieve infection, but this does not recapitulate sexual HIV transmission. High dose infection has the unwanted effect of masking protective effects of an otherwise efficacious vaccine [78]. On the other hand, recent advances in experimental protocols have resulted in a number of studies adopting two low-dose challenge of SIVmac251that imitates natural HIV infection that offered some protection in contrast to a high-dose group in rhesus macaques [78]. In another study, live hyperattenuated SIV viruses, induced a robust and rapid recall response following multi low-dose SIVmac239 infection in cynomolgus macaques but vaccination failed to induce sterilizing immunity, even though viral loads were dramatically reduced [79]. Vaccines against SIV can provide vaccinationinduced immune correlates but multiple low-dose challenges can result in evolving host responses that affect the protective outcome. This is exemplified by a $73 \%$ reduction in risk of infection in macaques challenged rectally with SIVmac251, which is attributed to innate antiviral signalling induced by the first challenge followed by vaccine boost-elicited antibody response [80]. Higher diversity of SIV variants was seen in macaques challenged orally with high dose SIV compared to a low-dose challenge, which reflects natural infection by HIV. Interventions applied during the eclipse phase, which is the delay in viral and innate immune responses, is more likely to be successful when oral low-dose SIV inoculations are part of the vaccine trial [81].

However, the low-dose approach is also fraught with problems such as the difficulty in identifying vaccine-induced immune responses from immune responses stemming from repeated exposures to SIV. Also, the timing of infection and tissue sampling procedures that require identification of the precise sequence of challenges that lead to infection will be hard to identify. Challenging animals with a low dose of SIV several times in a short duration (rapid, repeated low-dose) in cynomolgus macaques allow examination of early acute events while using a low-dose challenge. Moreover, because of the nature of the protocol, there is a clearly defined duration between intervention and challenge allowing for studies related to longitudinal efficacy of microbicidal treatments and vaccine trials [82]. In the presence of neutralizing or blocking antibodies, even high doses of highly pathogenic SIVmac239 strain can be controlled [83]. This suggests that a highly efficacious vaccine that induces both cellular and humoral immunity can overcome some of the barriers induced by the viral strain, dose, macaque strain and other variables in a vaccine trial.

\section{CONCLUSION}

Despite a ban on export of Indian rhesus macaques from India, primate-breeding facilities in North America have ensured a steady and consistent supply of this species for biomedical research purposes. Therefore, the use and development of other macaque species such as cynomolgus and pigtail macaques, as HIV models is dependent on the tropism and host specificity of SIV strains and of candidate vaccine vectors. Genomic characterization of animals and their allocation in vaccine trials are a necessity when elucidating the protective mechanisms attributed to vaccines in macaques. The ease of genome sequencing in terms of cost and technology has further benefited the macaque biomedical research community in terms of MHC allele databases of various macaques enabling identification of those that confer protection against SIV infection. The species-specific nature of vaccine vectors should complement the immunogenetics and anatomical features of the macaque model being used for that study. Thus, vaccine studies are influenced by host genes as well as immunological correlates of protection specific to vectors employed. Lastly, care must be taken to ensure that animals are well-characterized and obtained from reputed sources. 


\begin{tabular}{|c|c|c|c|c|c|c|c|c|c|}
\hline 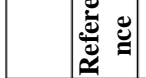 & 离 & & & & $\underset{\Phi}{F}$ & & & & \\
\hline 喅 & 官 & & & & $\overleftrightarrow{\mathrm{z}}$ & & & & \\
\hline 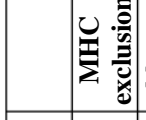 & 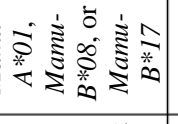 & & & & 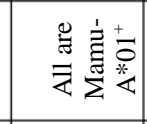 & & & & \\
\hline 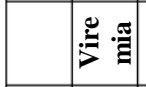 & 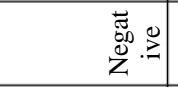 & & & & 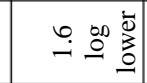 & & & & \\
\hline 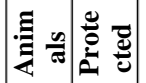 & $\overrightarrow{:} \simeq$ & & $\begin{array}{l}\vec{b} \\
\infty \\
\infty\end{array}$ & & 0 & 0 & 。 & 0 & 。 \\
\hline $\bar{\partial} \bar{\varepsilon}$ & 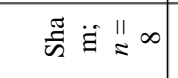 & & & & & & & & \\
\hline 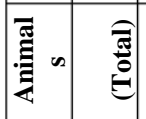 & $\approx$ & & i & & . & 0 & $\circ$ & 6 & 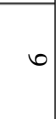 \\
\hline 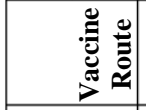 & $\Xi$ & & & & $\Xi$ & U & $\Xi$ & $\Xi$ & $\Xi$ \\
\hline 竎 & 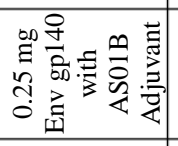 & 容密 & 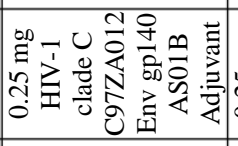 & 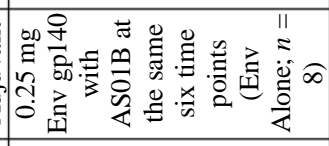 & 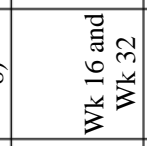 & & & & \\
\hline 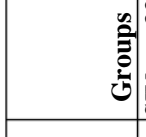 & 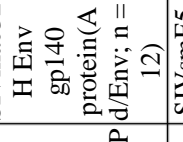 & 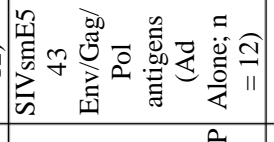 & & & & & & & \\
\hline : & 总 & 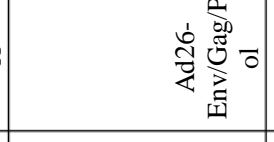 & & & : & & & & \\
\hline 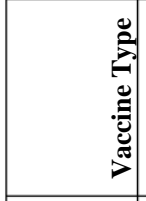 & 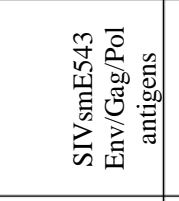 & & 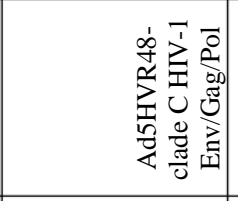 & & 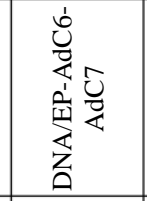 & 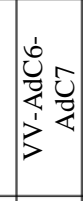 & 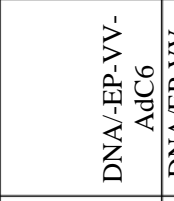 & 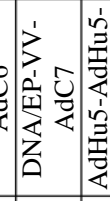 & $\begin{array}{l}1 \\
\\
\end{array}$ \\
\hline 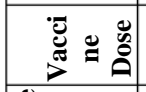 & 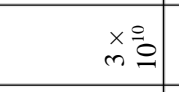 & & & & $\bar{\vdots}$ & $\hat{s}$ & $\overline{\bar{s}}$ & $\bar{\vdots}$ & 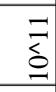 \\
\hline 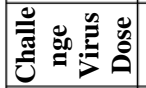 & 윰음 & & 80 & & 융류 & & & & \\
\hline 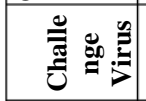 & $\sum_{n=0}^{n} \bar{g}$ & & 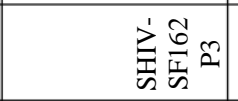 & & 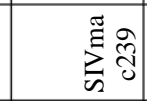 & & & & \\
\hline 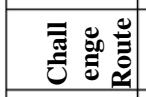 & $\cong$ & & & & $\cong$ & & & & \\
\hline 墕 & 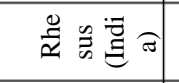 & & & & 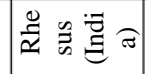 & & & & \\
\hline : & 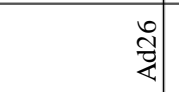 & & 常 & & $\frac{\vartheta}{q}$ & s & 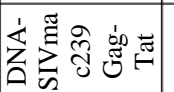 & $=3$ & \\
\hline z) & -1 & & & & $N$ & 4 & & & \\
\hline
\end{tabular}

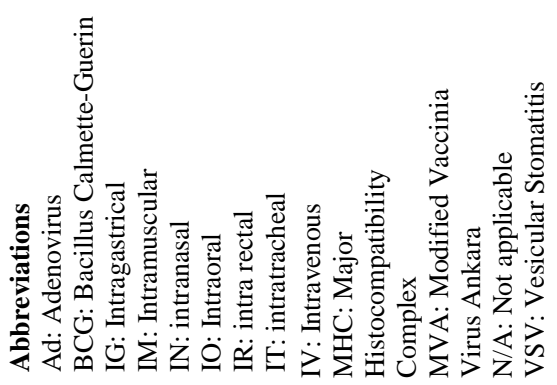




\begin{tabular}{|c|c|c|c|c|c|c|c|c|c|c|}
\hline 这 & $\stackrel{\infty}{\infty}$ & & & & $\underset{\infty}{\infty}$ & & 동 & & तु & \\
\hline ह & & $\mathbb{z}$ & & & $\mathbb{z}$ & & $\mathbb{z}$ & & 苞 & \\
\hline 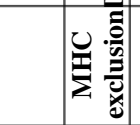 & & 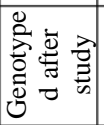 & 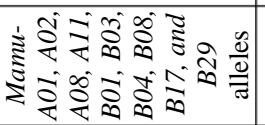 & & 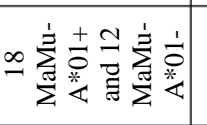 & & 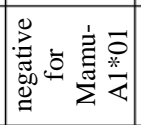 & & $\underline{v}$ & \\
\hline 竞 & & $\sum_{3}^{0}-$ & & & 童- & & & モn & 产 & \\
\hline 言电高 & 0 & & & & $\stackrel{\vec{c}}{\mathrm{~N}}$ 의 & & & $\begin{array}{l}\infty \\
\stackrel{4}{0} \\
-\end{array}$ & 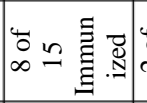 & $\dot{0}$ \\
\hline ชี & & & & & IIIO & & $\stackrel{\tilde{\omega}}{2}$ & & $\because$ & \\
\hline 吾 & $\nabla$ & & & & & & $\nabla$ & $\infty$ & 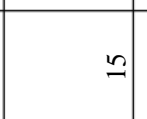 & \\
\hline 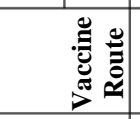 & 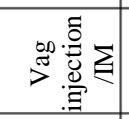 & 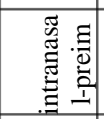 & & & $\Sigma$ & & $\Sigma$ & $\begin{array}{l}z \\
\varrho \\
\varrho\end{array}$ & un & \\
\hline 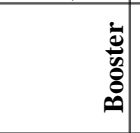 & 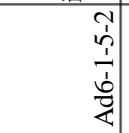 & & & & $\begin{array}{l}\stackrel{\mathrm{N}}{ } \\
\overrightarrow{3}\end{array}$ & & $\frac{n}{4}$ & & 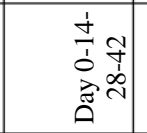 & \\
\hline 気 & & & & & 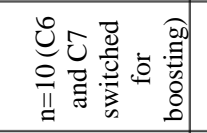 & & & & & \\
\hline : & & & & & : & & 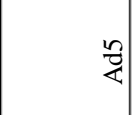 & & & \\
\hline : & 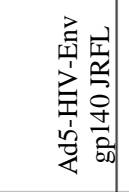 & & & & 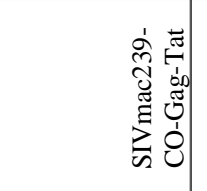 & & 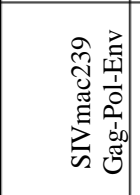 & & 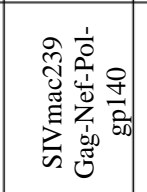 & \\
\hline 芯 & $\bar{\Xi}$ & & & & $\overline{\underline{s}}$ & & $\bar{\delta}$ & $\underline{\hat{\sigma}}$ & $\begin{array}{l}0 \\
\vdots \\
\vdots \\
\end{array}$ & \\
\hline 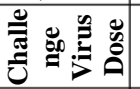 & 8 & & & & 8 塄 & & \&̊ㅇำ & & \& & \\
\hline 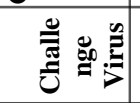 & 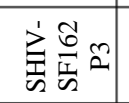 & & & & 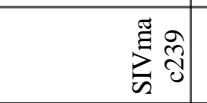 & & 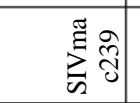 & & 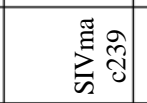 & \\
\hline 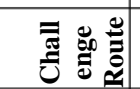 & $\cong$ & & & & $\cong$ & & $\cong$ & & $\cong$ & \\
\hline ฮू Е & 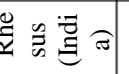 & & & & 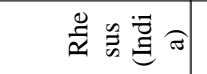 & & 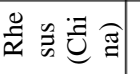 & & 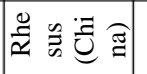 & \\
\hline : & 워 & $\vec{\psi}$ & $\frac{8}{4}$ & वे & ț & 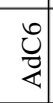 & 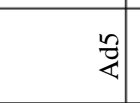 & 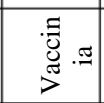 & ? & \\
\hline & $m$ & & & & + & & in & & 6 & \\
\hline
\end{tabular}




\begin{tabular}{|c|c|c|c|c|c|c|c|c|c|c|c|}
\hline 这 : & $\stackrel{\infty}{\infty}$ & & & & 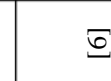 & $\stackrel{\bar{\alpha}}{0}$ & 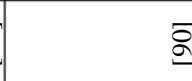 & $\bar{\Xi}$ & 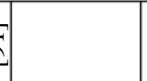 & $\bar{\delta}$ & \\
\hline 贯 & $\mathbb{z}$ & & & & 宜 & $\mathbb{z}$ & $\stackrel{\mathbb{z}}{\mathrm{z}}$ & $\overleftrightarrow{z}$ & & 苴 & \\
\hline 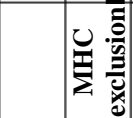 & 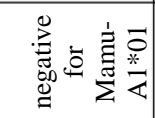 & & & & $\underbrace{0}$ & 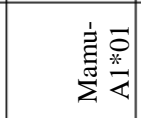 & 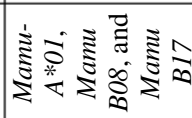 & 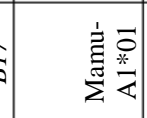 & & $\stackrel{0}{\Sigma}$ & \\
\hline$\cong$ & ت ت & & & & $\overbrace{0}^{0}-$ & $\sum_{0}^{0}-$ & 荾- & 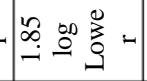 & & 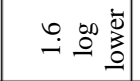 & \\
\hline 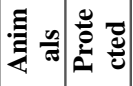 & 0 & & & & & & & & & $\sim$ & \\
\hline ชี & 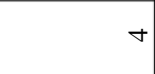 & & & & $\infty$ & in & $\infty$ & $m$ & & $\infty$ & \\
\hline 产 & $\nabla$ & † & 6 & $n$ & $a$ & in & $\stackrel{0}{2}$ & in & & $\infty$ & \\
\hline 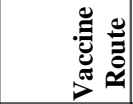 & 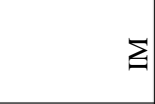 & & & & 急鸹 & 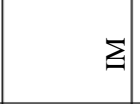 & $\sum$ & $\geq$ & & $\Sigma$ & \\
\hline 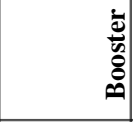 & & & & & & & 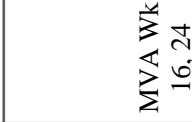 & & & & \\
\hline & 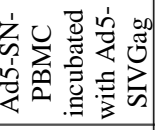 & 离 & 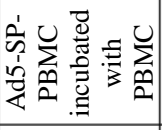 & $\frac{1}{2}$ & 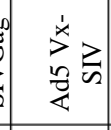 & & & & & & \\
\hline$\stackrel{\Xi}{E}$ & & & & & 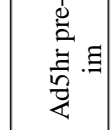 & & 芝兑 & & & & \\
\hline 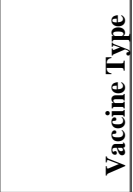 & 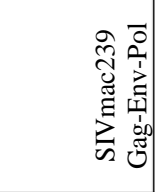 & & & & 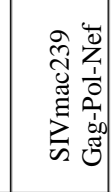 & 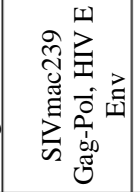 & 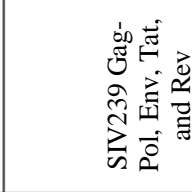 & 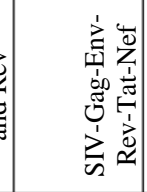 & & 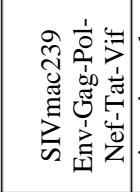 & 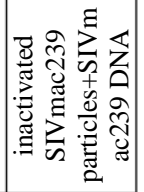 \\
\hline 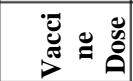 & $\bar{s}$ & & & & $\stackrel{0}{\vdots}$ & $\stackrel{\infty}{0}^{\infty}$ & $\sum^{\infty}$ & $\sum_{0}^{n}$ & 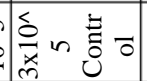 & 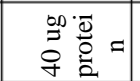 & \\
\hline 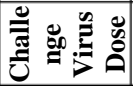 & $\underset{8}{8}$ & & & & 高。 & $\infty$ 胃 & $\bar{z}$ & 융 & & 윰요 & \\
\hline 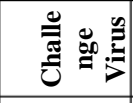 & 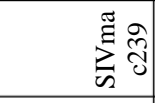 & & & & 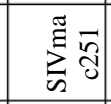 & 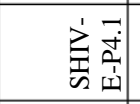 & $\sum_{\tilde{n}}^{\mathfrak{g}} \overline{\mathrm{g}}$ & $\sum_{\tilde{\omega}}^{\stackrel{\pi}{\Xi}}$ ণิ & & 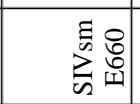 & \\
\hline 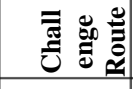 & $\geq$ & & & & 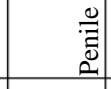 & $\geq$ & $\cong$ & $\geq$ & & $\cong$ & \\
\hline Еू & 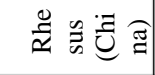 & & & & 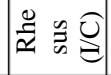 & 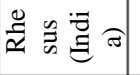 & 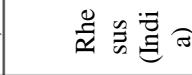 & 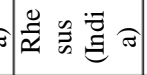 & & 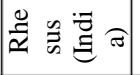 & \\
\hline 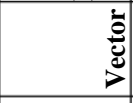 & $\frac{2}{4}$ & & & & 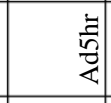 & 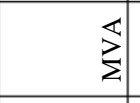 & 齐文 & 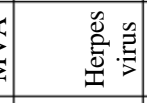 & & 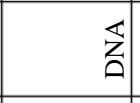 & \\
\hline$\stackrel{2}{z}$ & $r$ & & & & $\infty$ & $a$ & e & $=$ & & $\approx$ & \\
\hline
\end{tabular}




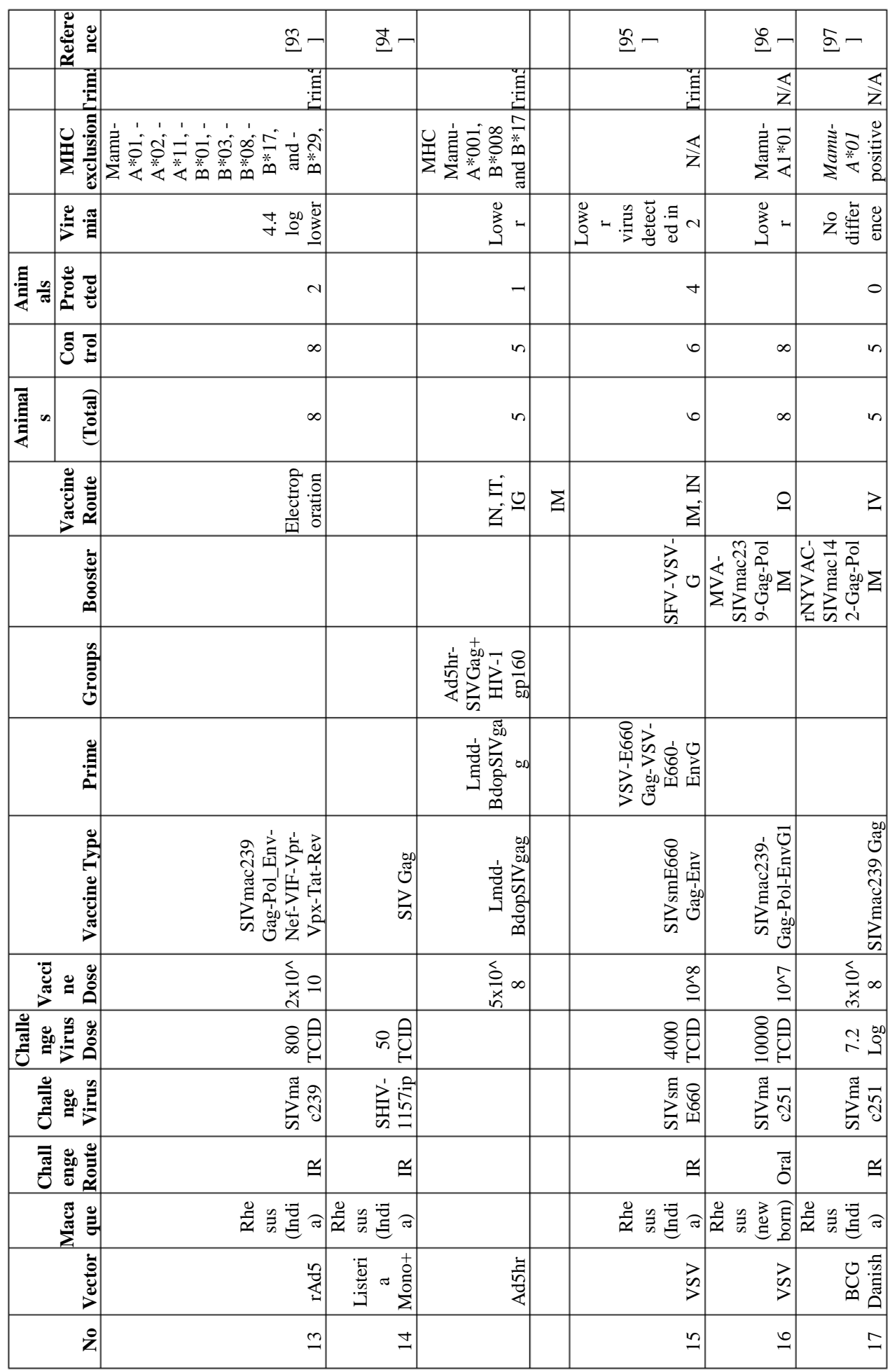




\begin{tabular}{|c|c|c|c|c|c|c|c|c|c|}
\hline 递 : & $\stackrel{\infty}{\varrho}-$ & & & & $\cong-$ & & $\sqrt{n}-$ & & $\sqrt{n}-$ \\
\hline 喅 & 害 & & & $\mathbb{z}$ & & & 思 & & $\mathbb{4}$ \\
\hline 语: & 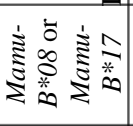 & & & 递 & 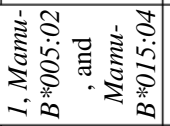 & & 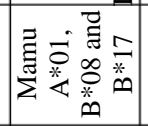 & & $\overleftrightarrow{z}$ \\
\hline : & 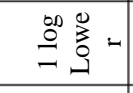 & & & & 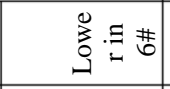 & & & & 产. \\
\hline 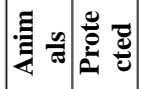 & & & & & & & $=$ & & \\
\hline $\mid \overline{\tilde{u}} \overline{\mathrm{g}}$ & $\infty$ & & & & in & & & & + \\
\hline 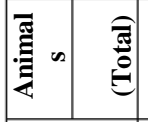 & $\infty$ & $\infty$ & $\infty$ & & $=$ & & $\stackrel{\Delta}{\Delta}$ & & $\simeq$ \\
\hline 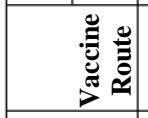 & 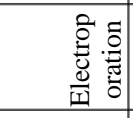 & u & & & $\S$ & $z$ & U & & $\begin{array}{l}0 \\
\vdots \\
\vdots\end{array}$ \\
\hline 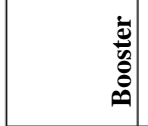 & & & & & & 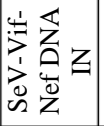 & & & \\
\hline 岂 & & & & & & & & & \\
\hline : & & & & & 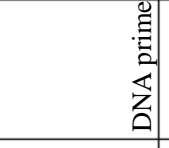 & & & & \\
\hline 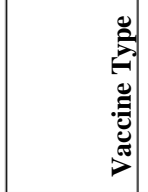 & 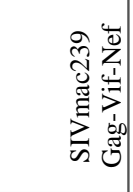 & & & & 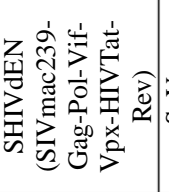 & 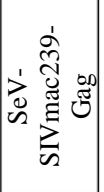 & 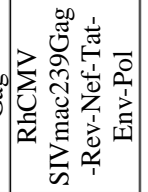 & $\begin{array}{l}z \\
2 \\
0 \\
0 \\
2\end{array}$ & 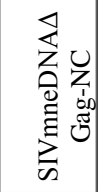 \\
\hline 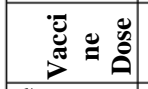 & & 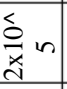 & $\bar{s}$ & & & 玄a & 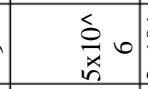 & $\sum_{\substack{x \\
\hdashline}}^{\infty}$ & \\
\hline 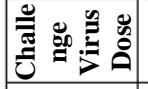 & 8 : & & & & 8 吾 & & 只虹 & & \\
\hline 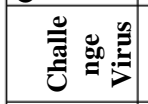 & 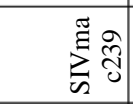 & & & & 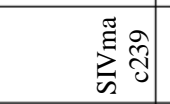 & & हี & & 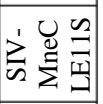 \\
\hline 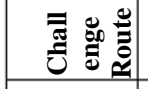 & $\cong$ & & & & $\geq$ & & $\cong$ & & $\cong$ \\
\hline$\sum_{\Sigma}^{\mathbb{J}}$ & 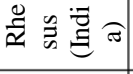 & & & & 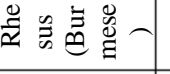 & & 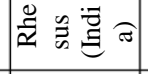 & & $\stackrel{500}{2} \cdot \vec{\sigma}$ \\
\hline$\stackrel{\grave{s}}{\grave{s}}$ & 艺 & $\sum_{i=1}^{ \pm}$ & 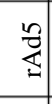 & & $\overleftrightarrow{z}$ & & 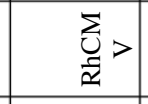 & & 苂 \\
\hline$\stackrel{2}{z}$ & $\stackrel{\infty}{=}$ & & & & 2 & & ते & & $\vec{\sim}$ \\
\hline
\end{tabular}




\section{CONFLICT OF INTEREST}

The authors declare that they have no conflict of interest.

\section{REFERENCES}

1. Brehm MA, Wiles MV, Greiner DL, Shultz LD. Generation of improved humanized mouse models for human infectious diseases. J Immunol Methods. 2014;410:3-17. doi:10.1016/j.jim.2014.02.011.

2. Antony JM, MacDonald KS. A critical analysis of the cynomolgus macaque, Macaca fascicularis, as a model to test HIV-1/SIV vaccine efficacy. Vaccine. doi:10.1016/j.vaccine.2014.12.004.

3. Baroncelli S, Negri DR, Michelini Z, Cara A. Macaca mulatta, fascicularis and nemestrina in AIDS vaccine development. Expert Rev Vaccines. 2008;7(9):1419-34. doi:10.1586/14760584.7.9.1419.

4. Osada N, Hashimoto K, Kameoka Y, Hirata M, Tanuma R, Uno Y et al. Large-scale analysis of Macaca fascicularis transcripts and inference of genetic divergence between $M$. fascicularis and $M$. mulatta. BMC Genomics. 2008;9:90. doi:10.1186/1471-2164-9-90.

5. Hayasaka K, Fujii K, Horai S. Molecular phylogeny of macaques: implications of nucleotide sequences from an 896-base pair region of mitochondrial DNA. Molecular biology and evolution. 1996;13(7):1044-53. 6. Qureshi H, Ma ZM, Huang Y, Hodge G, Thomas MA, DiPasquale J et al. Low-dose penile SIVmac251 exposure of rhesus macaques infected with adenovirus type 5 (Ad5) and then immunized with a replication-defective Ad5-based SIV gag/pol/nef vaccine recapitulates the results of the phase IIb step trial of a similar HIV-1 vaccine. J Virol. 2012;86(4):2239-50. doi:10.1128/JVI.06175-11.

7. Yan G, Zhang G, Fang X, Zhang Y, Li C, Ling F et al. Genome sequencing and comparison of two nonhuman primate animal models, the cynomolgus and Chinese rhesus macaques. Nat Biotechnol. 2011;29(11):1019-23. doi:10.1038/nbt.1992.

8. Osada N, Uno Y, Mineta K, Kameoka Y, Takahashi I, Terao K. Ancient genome-wide admixture extends beyond the current hybrid zone between Macaca fascicularis and M. mulatta. Mol Ecol. 2010;19(14):2884-95. doi:10.1111/j.1365-294X.2010.04687.x.

9. Bjornson-Hooper ZBF, G.K; Spitzer, M.H; Madhireddy, D; Mcllwain, D; Nolan, G.P. A comprehensive atlas of immunological differences between humans, mice and non-human primates. bioRxiv. 2020. doi:10.1101/574160.

10. Meyer C, Engelmann F, Arnold N, Krah DL, ter Meulen J, Haberthur K et al. Abortive intrabronchial infection of rhesus macaques with varicellazoster virus provides partial protection against simian varicella virus challenge. J Virol. 2015;89(3):1781-93. doi:10.1128/JVI.03124-14.

11. Willer DO, Ambagala AP, Pilon R, Chan JK, Fournier J, Brooks J et al. Experimental infection of Cynomolgus Macaques (Macaca fascicularis) with human varicella-zoster virus. J Virol. 2012;86(7):3626-34. doi:10.1128/JVI.06264-11.

12. Angie K. Marsh APA, Catia T. Perciani, Justen N. Hoffman Russell, Jacqueline K. Chan, Michelle Janes, Joseph M. Antony, Richard Pilon, Paul Sandstrom, David O. Willer, Kelly S. MacDonald. Examining the species-specificity of rhesus macaque cytomegalovirus ( $\mathrm{RhCMV}$ ) in cynomolgus macaques. PLoS One. 2015(in press).

13. Malouli D, Nakayasu ES, Viswanathan K, Camp DG, 2nd, Chang WL, Barry PA et al. Reevaluation of the coding potential and proteomic analysis of the BAC-derived rhesus cytomegalovirus strain 68-1. J Virol. 2012;86(17):8959-73. doi:10.1128/JVI.01132-12.

14. Breed MW, Elser SE, Torben W, Jordan AP, Aye PP, Midkiff C et al. Elite Control, Gut CD4 T Cell Sparing, and Enhanced Mucosal T Cell Responses in Macaca nemestrina Infected by a Simian Immunodeficiency Virus Lacking a gp41 Trafficking Motif. J Virol. 2015;89(20):10156-75. doi:10.1128/JVI.01134-15.

15. Iwamoto N, Takahashi N, Seki S, Nomura T, Yamamoto H, Inoue M et al. Control of simian immunodeficiency virus replication by vaccineinduced Gag- and Vif-specific CD8+ T cells. J Virol. 2014;88(1):425-33. doi:10.1128/JVI.02634-13.

16. Sharp PM, Hahn BH. Origins of HIV and the AIDS pandemic. Cold Spring Harb Perspect Med. 2011;1(1):a006841. doi:10.1101/cshperspect.a006841.

17. Joag SV, Stephens EB, Adams RJ, Foresman L, Narayan O. Pathogenesis of SIVmac infection in Chinese and Indian rhesus macaques: effects of splenectomy on virus burden. Virology. 1994;200(2):436-46. doi:10.1006/viro.1994.1207.

18. Marthas ML, Lu D, Penedo MC, Hendrickx AG, Miller CJ. Titration of an SIVmac251 stock by vaginal inoculation of Indian and Chinese origin rhesus macaques: transmission efficiency, viral loads, and antibody responses. AIDS Res Hum Retroviruses. 2001;17(15):1455-66. doi:10.1089/088922201753197123.

19. Ling B, Veazey RS, Luckay A, Penedo C, Xu K, Lifson JD et al. $\mathrm{SIV}(\mathrm{mac})$ pathogenesis in rhesus macaques of Chinese and Indian origin compared with primary HIV infections in humans. Aids. 2002;16(11):148996. doi:10.1097/00002030-200207260-00005.

20. Trichel AM, Rajakumar PA, Murphey-Corb M. Species-specific variation in SIV disease progression between Chinese and Indian subspecies of rhesus macaque. J Med Primatol. 2002;31(4-5):171-8. doi:10.1034/j.1600-0684.2002.02003.x.

21. Reimann KA, Parker RA, Seaman MS, Beaudry K, Beddall M, Peterson $\mathrm{L}$ et al. Pathogenicity of simian-human immunodeficiency virus SHIV89.6P and SIVmac is attenuated in cynomolgus macaques and associated with early T-lymphocyte responses. J Virol. 2005;79(14):8878-85. doi:10.1128/JVI.79.14.8878-8885.2005.

22. Marcondes MC, Penedo MC, Lanigan C, Hall D, Watry DD, Zandonatti $\mathrm{M}$ et al. Simian immunodeficiency virus-induced CD4+ T cell deficits in cytokine secretion profile are dependent on monkey origin. Viral Immunol. 2006;19(4):679-89. doi:10.1089/vim.2006.19.679.

23. Monceaux V, Viollet L, Petit F, Cumont MC, Kaufmann GR, Aubertin $\mathrm{AM}$ et al. CD4+ CCR5+ T-cell dynamics during simian immunodeficiency virus infection of Chinese rhesus macaques. J Virol. 2007;81(24):13865-75. doi:10.1128/JVI.00452-07.

24. Veazey RS. Microbicide safety/efficacy studies in animals: macaques and small animal models. Current opinion in HIV and AIDS. 2008;3(5):567-73. doi:10.1097/COH.0b013e32830891bb.

25. Otten RA, Adams DR, Kim CN, Jackson E, Pullium JK, Lee K et al. Multiple vaginal exposures to low doses of R5 simian-human immunodeficiency virus: strategy to study HIV preclinical interventions in nonhuman primates. J Infect Dis. 2005;191(2):164-73. doi:10.1086/426452. 26. Goode D, Aravantinou M, Jarl S, Truong R, Derby N, Guerra-Perez N et al. Sex hormones selectively impact the endocervical mucosal microenvironment: implications for HIV transmission. PLoS One. 2014:9(5):e97767. doi:10.1371/journal.pone.0097767.

27. Gordon SN, Kines RC, Kutsyna G, Ma ZM, Hryniewicz A, Roberts JN et al. Targeting the vaginal mucosa with human papillomavirus pseudovirion vaccines delivering simian immunodeficiency virus DNA. J Immunol. 2012;188(2):714-23. doi:10.4049/jimmunol.1101404.

28. Gordon SN, Doster MN, Kines RC, Keele BF, Brocca-Cofano E, Guan $\mathrm{Y}$ et al. Antibody to the gp120 V1/V2 loops and CD4+ and CD8+ T cell responses in protection from SIVmac251 vaginal acquisition and persistent viremia. J Immunol. 2014;193(12):6172-83. doi:10.4049/jimmunol.1401504.

29. Chenine AL, Siddappa NB, Kramer VG, Sciaranghella G, Rasmussen RA, Lee SJ et al. Relative transmissibility of an R5 clade C simian-human immunodeficiency virus across different mucosae in macaques parallels the relative risks of sexual HIV-1 transmission in humans via different routes. J Infect Dis. 2010;201(8):1155-63. doi:10.1086/651274.

30. Abrahams MR, Anderson JA, Giorgi EE, Seoighe C, Mlisana K, Ping LH et al. Quantitating the multiplicity of infection with human immunodeficiency virus type 1 subtype $\mathrm{C}$ reveals a non-poisson distribution of transmitted variants. J Virol. 2009;83(8):3556-67. doi:10.1128/JVI.02132-08.

31. Ma Z, Lu FX, Torten M, Miller CJ. The number and distribution of immune cells in the cervicovaginal mucosa remain constant throughout the menstrual cycle of rhesus macaques. Clin Immunol. 2001;100(2):240-9. doi:10.1006/clim.2001.5058.

32. Sodora DL, Gettie A, Miller CJ, Marx PA. Vaginal transmission of SIV: assessing infectivity and hormonal influences in macaques inoculated with cell-free and cell-associated viral stocks. AIDS Res Hum Retroviruses. 1998;14 Suppl 1:S119-23.

33. Klatt NR, Harris LD, Vinton CL, Sung H, Briant JA, Tabb B et al Compromised gastrointestinal integrity in pigtail macaques is associated with increased microbial translocation, immune activation, and IL-17 production in the absence of SIV infection. Mucosal Immunol. 2010;3(4):387-98. doi:10.1038/mi.2010.14.

34. Mohanram V, Demberg T, Musich T, Tuero I, Vargas-Inchaustegui DA, Miller-Novak L et al. B Cell Responses Associated with Vaccine-Induced Delayed SIVmac251 Acquisition in Female Rhesus Macaques. J Immunol. 2016;197(6):2316-24. doi:10.4049/jimmunol.1600544.

35. Stieh DJ, Maric D, Kelley ZL, Anderson MR, Hattaway HZ, Beilfuss BA et al. Vaginal challenge with an SIV-based dual reporter system reveals that infection can occur throughout the upper and lower female reproductive tract. PLoS pathogens. 2014;10(10):e1004440. doi:10.1371/journal.ppat.1004440. 
36. Smedley J, Turkbey B, Bernardo ML, Del Prete GQ, Estes JD, Griffiths GL et al. Tracking the luminal exposure and lymphatic drainage pathways of intravaginal and intrarectal inocula used in nonhuman primate models of HIV transmission. PLoS One. 2014;9(3):e92830. doi:10.1371/journal.pone.0092830.

37. Salle B, Brochard P, Bourry O, Mannioui A, Andrieu T, Prevot S et al. Infection of macaques after vaginal exposure to cell-associated simian immunodeficiency virus. J Infect Dis. 2010;202(3):337-44. doi:10.1086/653619.

38. Kolodkin-Gal D, Hulot SL, Korioth-Schmitz B, Gombos RB, Zheng Y, Owuor $\mathbf{J}$ et al. Efficiency of cell-free and cell-associated virus in mucosal transmission of human immunodeficiency virus type 1 and simian immunodeficiency virus. J Virol. 2013;87(24):13589-97. doi:10.1128/JVI.03108-12.

39. Bernard-Stoecklin S, Gommet C, Cavarelli M, Le Grand R. Nonhuman primate models for cell-associated simian immunodeficiency virus transmission: the need to better understand the complexity of HIV mucosal transmission. J Infect Dis. 2014;210 Suppl 3:S660-6. doi:10.1093/infdis/jiu536.

40. Stremlau M, Owens CM, Perron MJ, Kiessling M, Autissier P, Sodroski J. The cytoplasmic body component TRIM5alpha restricts HIV-1 infection in Old World monkeys. Nature. 2004;427(6977):848-53. doi:10.1038/nature02343.

41. Wilson SJ, Webb BL, Maplanka C, Newman RM, Verschoor EJ, Heeney JL et al. Rhesus macaque TRIM5 alleles have divergent antiretroviral specificities. J Virol. 2008;82(14):7243-7. doi:10.1128/JVI.00307-08.

42. Liao CH, Kuang YQ, Liu HL, Zheng YT, Su B. A novel fusion gene, TRIM5-Cyclophilin $A$ in the pig-tailed macaque determines its susceptibility to HIV-1 infection. Aids. 2007;21 Suppl 8:S19-26. doi:10.1097/01.aids.0000304692.09143.1b.

43. de Groot NG, Heijmans CM, Koopman G, Verschoor EJ, Bogers WM, Bontrop RE. TRIM5 allelic polymorphism in macaque species/populations of different geographic origins: its impact on SIV vaccine studies. Tissue antigens. 2011;78(4):256-62. doi:10.1111/j.1399-0039.2011.01768.x.

44. Greene JM, Wiseman RW, Lank SM, Bimber BN, Karl JA, Burwitz BJ et al. Differential MHC class I expression in distinct leukocyte subsets. BMC Immunol. 2011;12:39. doi:10.1186/1471-2172-12-39.

45. Smith MZ, Fernandez CS, Chung A, Dale CJ, De Rose R, Lin J et al. The pigtail macaque MHC class I allele Mane-A*10 presents an immundominant SIV Gag epitope: identification, tetramer development and implications of immune escape and reversion. J Med Primatol. 2005;34(56):282-93. doi:10.1111/j.1600-0684.2005.00126.x.

46. Gooneratne SL, Alinejad-Rokny H, Ebrahimi D, Bohn PS, Wiseman $\mathrm{RW}$, O'Connor $\mathrm{DH}$ et al. Linking pig-tailed macaque major histocompatibility complex class I haplotypes and cytotoxic T lymphocyte escape mutations in simian immunodeficiency virus infection. J Virol. 2014;88(24):14310-25. doi:10.1128/JVI.02428-14.

47. Carrington M, O'Brien SJ. The influence of HLA genotype on AIDS Annual review of medicine. 2003;54:535-51. doi:10.1146/annurev.med.54.101601.152346.

48. Watanabe A, Shiina T, Shimizu S, Hosomichi K, Yanagiya K, Kita YF et al. A BAC-based contig map of the cynomolgus macaque (Macaca fascicularis) major histocompatibility complex genomic region. Genomics. 2007;89(3):402-12. doi:10.1016/j.ygeno.2006.11.002.

49. Wiseman RW, Karl JA, Bohn PS, Nimityongskul FA, Starrett GJ, O'Connor DH. Haplessly hoping: macaque major histocompatibility complex made easy. ILAR journal / National Research Council, Institute of Laboratory Animal Resources. 2013;54(2):196-210. doi:10.1093/ilar/ilt036. 50. Muhl T, Krawczak M, Ten Haaft P, Hunsmann G, Sauermann U. MHC class I alleles influence set-point viral load and survival time in simian immunodeficiency virus-infected rhesus monkeys. J Immunol. 2002;169(6):3438-46. doi:10.4049/jimmunol.169.6.3438.

51. Gorelick RJ, Lifson JD, Yovandich JL, Rossio JL, Piatak M, Jr., Scarzello AJ et al. Mucosal challenge of Macaca nemestrina with simian immunodeficiency virus (SIV) following SIV nucleocapsid mutant DNA vaccination. J Med Primatol. 2000;29(3-4):209-19. doi:10.1034/j.16000684.2000.290314.x.

52. Prentice HA, Tomaras GD, Geraghty DE, Apps R, Fong Y, Ehrenberg PK et al. HLA class II genes modulate vaccine-induced antibody responses to affect HIV-1 acquisition. Sci Transl Med. 2015;7(296):296ra112. doi:10.1126/scitranslmed.aab4005.

53. Michopoulos V, Checchi M, Sharpe D, Wilson ME. Estradiol effects on behavior and serum oxytocin are modified by social status and polymorphisms in the serotonin transporter gene in female rhesus monkeys. Horm Behav. 2011;59(4):528-35. doi:10.1016/j.yhbeh.2011.02.002.
54. Morgan D, Grant KA, Gage HD, Mach RH, Kaplan JR, Prioleau O et al. Social dominance in monkeys: dopamine D2 receptors and cocaine selfadministration. Nat Neurosci. 2002;5(2):169-74. doi:10.1038/nn798.

55. Paiardini M, Hoffman J, Cervasi B, Ortiz AM, Stroud F, Silvestri G et al. T-cell phenotypic and functional changes associated with social subordination and gene polymorphisms in the serotonin reuptake transporter in female rhesus monkeys. Brain Behav Immun. 2009;23(2):286-93. doi:10.1016/j.bbi.2008.10.006.

56. Vargas-Inchaustegui DA, Tuero I, Mohanram V, Musich T, Pegu P Valentin A et al. Humoral immunity induced by mucosal and/or systemic SIV-specific vaccine platforms suggests novel combinatorial approaches for enhancing responses. Clin Immunol. 2014;153(2):308-22. doi:10.1016/j.clim.2014.05.008.

57. Hansen SG, Ford JC, Lewis MS, Ventura AB, Hughes CM, CoyneJohnson L et al. Profound early control of highly pathogenic SIV by an effector memory T-cell vaccine. Nature. 2011;473(7348):523-7. doi:10.1038/nature10003.

58. Barouch DH, Alter G, Broge T, Linde C, Ackerman ME, Brown EP et al. Protective efficacy of adenovirus/protein vaccines against SIV challenges in rhesus monkeys. Science. 2015;349(6245):320-4. doi:10.1126/science.aab3886.

59. Gomez-Roman VR, Grimes GJ, Jr., Potti GK, Peng B, Demberg T, Gravlin $\mathrm{L}$ et al. Oral delivery of replication-competent adenovirus vectors is well tolerated by SIV- and SHIV-infected rhesus macaques. Vaccine. 2006;24(23):5064-72. doi:10.1016/j.vaccine.2006.03.048

60. Iyer SS, Gangadhara S, Victor B, Shen X, Chen X, Nabi R et al. VirusLike Particles Displaying Trimeric Simian Immunodeficiency Virus (SIV) Envelope gp160 Enhance the Breadth of DNA/Modified Vaccinia Virus Ankara SIV Vaccine-Induced Antibody Responses in Rhesus Macaques. J Virol. 2016;90(19):8842-54. doi:10.1128/JVI.01163-16.

61. Hansen SG, Piatak M, Jr., Ventura AB, Hughes CM, Gilbride RM, Ford JC et al. Immune clearance of highly pathogenic SIV infection. Nature. 2013;502(7469):100-4. doi:10.1038/nature12519.

62. Gabitzsch ES, Balint-Junior JP, Xu Y, Balcaitis S, Sanders-Beer B, Karl $\mathrm{J}$ et al. Control of SIV infection and subsequent induction of pandemic H1N1 immunity in rhesus macaques using an Ad5 [E1-, E2b-] vector platform. Vaccine.

2012;30(50):7265-70 doi:10.1016/j.vaccine.2012.09.058.

63. Wilson NA, Keele BF, Reed JS, Piaskowski SM, MacNair CE, Bett AJ et al. Vaccine-induced cellular responses control simian immunodeficiency virus replication after heterologous challenge. J Virol. 2009;83(13):650821. doi:10.1128/JVI.00272-09.

64. Lu Y, Pauza CD, Lu X, Montefiori DC, Miller CJ. Rhesus macaques that become systemically infected with pathogenic SHIV 89.6-PD after intravenous, rectal, or vaginal inoculation and fail to make an antiviral antibody response rapidly develop AIDS. Journal of acquired immune deficiency syndromes and human retrovirology : official publication of the International Retrovirology Association. 1998;19(1):6-18.

65. Reimann KA, Li JT, Voss G, Lekutis C, Tenner-Racz K, Racz P et al An env gene derived from a primary human immunodeficiency virus type 1 isolate confers high in vivo replicative capacity to a chimeric simian/human immunodeficiency virus in rhesus monkeys. J Virol. 1996;70(5):3198-206. 66. Borsetti A, Baroncelli S, Maggiorella MT, Bellino S, Moretti S, Sernicola $L$ et al. Viral outcome of simian-human immunodeficiency virus SHIV-89.6P adapted to cynomolgus monkeys. Arch Virol. 2008;153(3):463-72. doi:10.1007/s00705-007-0009-2.

67. Zhang Y, Lou B, Lal RB, Gettie A, Marx PA, Moore JP. Use of inhibitors to evaluate coreceptor usage by simian and simian/human immunodeficiency viruses and human immunodeficiency virus type 2 in primary cells. J Virol. 2000;74(15):6893-910

68. Haynes BF, Gilbert PB, McElrath MJ, Zolla-Pazner S, Tomaras GD, Alam SM et al. Immune-correlates analysis of an HIV-1 vaccine efficacy trial. N Engl J Med. 2012;366(14):1275-86. doi:10.1056/NEJMoa1113425. 69. Song RJ, Chenine AL, Rasmussen RA, Ruprecht CR, Mirshahidi S, Grisson RD et al. Molecularly cloned SHIV-1157ipd3N4: a highly replication- competent, mucosally transmissible R5 simian-human immunodeficiency virus encoding HIV clade C Env. J Virol. 2006;80(17):8729-38. doi:10.1128/JVI.00558-06.

70. Kuller L, Thompson J, Watanabe R, Iskandriati D, Alpers CE, Morton WR et al. Mucosal antibody expression following rapid SIV(Mne) dissemination in intrarectally infected Macaca nemestrina. AIDS Res Hum Retroviruses. 1998;14(15):1345-56. doi:10.1089/aid.1998.14.1345.

71. ten Haaft P, Almond N, Biberfeld G, Cafaro A, Cranage M, Ensoli B et al. Comparison of early plasma RNA loads in different macaque species and the impact of different routes of exposure on SIV/SHIV infection. $\mathrm{J}$ Med Primatol. 2001;30(4):207-14. 
72. Patterson LJ, Kuate S, Daltabuit-Test M, Li Q, Xiao P, McKinnon K et al. Replicating adenovirus-simian immunodeficiency virus (SIV) vectors efficiently prime SIV-specific systemic and mucosal immune responses by targeting myeloid dendritic cells and persisting in rectal macrophages, regardless of immunization route. Clin Vaccine Immunol. 2012;19(5):62937. doi:10.1128/CVI.00010-12.

73. Xiao P, Patterson LJ, Kuate S, Brocca-Cofano E, Thomas MA, Venzon $\mathrm{D}$ et al. Replicating adenovirus-simian immunodeficiency virus (SIV) recombinant priming and envelope protein boosting elicits localized, mucosal $\operatorname{IgA}$ immunity in rhesus macaques correlated with delayed acquisition following a repeated low-dose rectal SIV(mac251) challenge. J Virol. 2012;86(8):4644-57. doi:10.1128/JVI.06812-11.

74. Stevceva L, Alvarez X, Lackner AA, Tryniszewska E, Kelsall B, Nacsa $\mathrm{J}$ et al. Both mucosal and systemic routes of immunization with the live, attenuated NYVAC/simian immunodeficiency virus SIV(gpe) recombinant vaccine result in gag-specific CD8(+) T-cell responses in mucosal tissues of macaques. J Virol. 2002;76(22):11659-76. doi:10.1128/jvi.76.22.1165911676.2002.

75. Belyakov IM, Hel Z, Kelsall B, Kuznetsov VA, Ahlers JD, Nacsa J et al. Mucosal AIDS vaccine reduces disease and viral load in gut reservoir and blood after mucosal infection of macaques. Nat Med. 2001;7(12):13206. doi:10.1038/nm1201-1320.

76. Ma ZM, Dutra J, Fritts L, Miller CJ. Lymphatic Dissemination of Simian Immunodeficiency Virus after Penile Inoculation. J Virol. 2016;90(8):4093-104. doi:10.1128/JVI.02947-15.

77. Boily MC, Baggaley RF, Wang L, Masse B, White RG, Hayes RJ et al. Heterosexual risk of HIV-1 infection per sexual act: systematic review and meta-analysis of observational studies. Lancet Infect Dis. 2009;9(2):118-29. doi:10.1016/S1473-3099(09)70021-0.

78. Vaccari M, Keele BF, Bosinger SE, Doster MN, Ma ZM, Pollara J et al. Protection afforded by an HIV vaccine candidate in macaques depends on the dose of SIVmac251 at challenge exposure. J Virol. 2013;87(6):3538-48. doi:10.1128/JVI.02863-12.

79. Willer DO, Guan Y, Luscher MA, Li B, Pilon R, Fournier J et al. Multilow-dose mucosal simian immunodeficiency virus SIVmac239 challenge of cynomolgus macaques immunized with "hyperattenuated" SIV constructs. J Virol. 2010;84(5):2304-17. doi:10.1128/JVI.01995-09.

80. Selinger C, Strbo N, Gonzalez L, Aicher L, Weiss JM, Law GL et al. Multiple low-dose challenges in a rhesus macaque AIDS vaccine trial result in an evolving host response that affects protective outcome. Clin Vaccine Immunol. 2014;21(12):1650-60. doi:10.1128/CVI.00455-14.

81. Durudas A, Chen HL, Gasper MA, Sundaravaradan V, Milush JM, Silvestri $\mathrm{G}$ et al. Differential innate immune responses to low or high dose oral SIV challenge in Rhesus macaques. Curr HIV Res. 2011;9(5):276-88. doi:10.2174/157016211797635928.

82. Greene JM, Weiler AM, Reynolds MR, Cain BT, Pham NH, Ericsen AJ et al. Rapid, repeated, low-dose challenges with SIVmac239 infect animals in a condensed challenge window. Retrovirology. 2014;11:66. doi:10.1186/s12977-014-0066-z.

83. Poignard P, Moldt B, Maloveste K, Campos N, Olson WC, Rakasz E et al. Protection against high-dose highly pathogenic mucosal SIV challenge at very low serum neutralizing titers of the antibody-like molecule CD4IgG2. PLoS One. 2012;7(7):e42209. doi:10.1371/journal.pone.0042209.

84. Carnathan DG, Wetzel KS, Yu J, Lee ST, Johnson BA, Paiardini M et al. Activated CD4+CCR5+ T cells in the rectum predict increased SIV acquisition in SIVGag/Tat-vaccinated rhesus macaques. Proc Natl Acad Sci U S A. 2015;112(2):518-23. doi:10.1073/pnas.1407466112.

85. Weaver EA, Nehete PN, Nehete BP, Yang G, Buchl SJ, Hanley PW et al. Comparison of systemic and mucosal immunization with helperdependent adenoviruses for vaccination against mucosal challenge with SHIV. PLoS One. 2013;8(7):e67574. doi:10.1371/journal.pone.0067574.
86. Cervasi B, Carnathan DG, Sheehan KM, Micci L, Paiardini M, Kurupati $\mathrm{R}$ et al. Immunological and virological analyses of rhesus macaques immunized with chimpanzee adenoviruses expressing the simian immunodeficiency virus Gag/Tat fusion protein and challenged intrarectally with repeated low doses of SIVmac. J Virol. 2013;87(17):9420-30. doi:10.1128/JVI.01456-13.

87. Sun C, Chen Z, Tang X, Zhang Y, Feng L, Du Y et al. Mucosal priming with a replicating-vaccinia virus-based vaccine elicits protective immunity to simian immunodeficiency virus challenge in rhesus monkeys. J Virol. 2013;87(10):5669-77. doi:10.1128/JVI.03247-12.

88. Sun C, Feng L, Zhang Y, Xiao L, Pan W, Li C et al. Circumventing antivector immunity by using adenovirus-infected blood cells for repeated application of adenovirus-vectored vaccines: proof of concept in rhesus macaques. J Virol. 2012;86(20):11031-42. doi:10.1128/JVI.00783-12.

89. Cox JH, Ferrari MG, Earl P, Lane JR, Jagodzinski LL, Polonis VR et al. Inclusion of a CRF01_AE HIV envelope protein boost with a DNA/MVA prime-boost vaccine: Impact on humoral and cellular immunogenicity and viral load reduction after SHIV-E challenge. Vaccine. 2012;30(10):183040. doi:10.1016/j.vaccine.2011.12.131.

90. Kannanganat S, Nigam P, Velu V, Earl PL, Lai L, Chennareddi L et al. Preexisting vaccinia virus immunity decreases SIV-specific cellular immunity but does not diminish humoral immunity and efficacy of a DNA/MVA vaccine. J Immunol. 2010;185(12):7262-73. doi:10.4049/jimmunol.1000751.

91. Bilello JP, Manrique JM, Shin YC, Lauer W, Li W, Lifson JD et al. Vaccine protection against simian immunodeficiency virus in monkeys using recombinant gamma-2 herpesvirus. J Virol. 2011;85(23):12708-20. doi:10.1128/JVI.00865-11.

92. Patel V, Jalah R, Kulkarni V, Valentin A, Rosati M, Alicea C et al. DNA and virus particle vaccination protects against acquisition and confers control of viremia upon heterologous simian immunodeficiency virus challenge. Proc Natl Acad Sci U S A. 2013;110(8):2975-80. doi:10.1073/pnas.1215393110.

93. Winstone N, Wilson AJ, Morrow G, Boggiano C, Chiuchiolo MJ, Lopez M et al. Enhanced control of pathogenic Simian immunodeficiency virus SIVmac239 replication in macaques immunized with an interleukin12 plasmid and a DNA prime-viral vector boost vaccine regimen. J Virol. 2011;85(18):9578-87. doi:10.1128/JVI.05060-11.

94. Lakhashe SK, Velu V, Sciaranghella G, Siddappa NB, Dipasquale JM, Hemashettar $\mathrm{G}$ et al. Prime-boost vaccination with heterologous live vectors encoding SIV gag and multimeric HIV-1 gp160 protein: efficacy against repeated mucosal R5 clade C SHIV challenges. Vaccine. 2011;29(34):5611-22. doi:10.1016/j.vaccine.2011.06.017.

95. Gambhira R, Keele BF, Schell JB, Hunter MJ, Dufour JP, Montefiori DC et al. Transmitted/founder simian immunodeficiency virus envelope sequences in vesicular stomatitis and Semliki forest virus vector immunized rhesus macaques. PLoS One. 2014;9(10):e109678. doi:10.1371/journal.pone.0109678.

96. Marthas ML, Van Rompay KK, Abbott Z, Earl P, Buonocore-Buzzelli L, Moss B et al. Partial efficacy of a VSV-SIV/MVA-SIV vaccine regimen against oral SIV challenge in infant macaques. Vaccine. 2011;29(17):312437. doi:10.1016/j.vaccine.2011.02.051.

97. Sixsmith JD, Panas MW, Lee S, Gillard GO, White K, Lifton MA et al. Recombinant Mycobacterium bovis bacillus Calmette-Guerin vectors prime for strong cellular responses to simian immunodeficiency virus gag in rhesus macaques. Clin Vaccine Immunol. 2014;21(10):1385-95. doi:10.1128/CVI.00324-14.

98. Martins MA, Wilson NA, Piaskowski SM, Weisgrau KL, Furlott JR, Bonaldo MC et al. Vaccination with Gag, Vif, and Nef gene fragments affords partial control of viral replication after mucosal challenge with SIVmac239. J Virol. 2014;88(13):7493-516. doi:10.1128/JVI.00601-14. 